Supporting Information

for

\title{
Formation of 1,10-phenanthroline- $N, N$ '-dioxide under mild conditions: the kinetics and mechanism of the oxidation of 1,10-phenanthroline by peroxomonosulfate ion (Oxone)
}

Gábor Bellér $^{\dagger *}$, Mária Szabó ${ }^{\dagger}$, Gábor Lente $^{\ddagger}$ and István Fábián ${ }^{\ddagger}$

${ }^{\dagger}$ MTA-DE Homogeneous Catalysis and Reaction Mechanisms Research Group, University of Debrecen, H-4032 Debrecen, Egyetem tér 1, Hungary

${ }^{\ddagger}$ Department of Inorganic and Analytical Chemistry, University of Debrecen, H-4032 Debrecen, Egyetem tér 1, Hungary

e-mail: beller.gabor@science.unideb.hu, Tel: + 3652 512-900/22327, Fax: + 3652 489-667

\section{TABLE OF CONTENT}

\section{Figures}

Figure S1. Spectrophotometric determination of the stoichiometry of the reaction of phen and PMS ....3

Figure S2. Kinetic traces of the reaction of phen and PMS under strongly acidic conditions. .............. 3

Figure S3. Dependence of the pseudo-first order rate constants $\left(k_{\mathrm{obs}}\right)$ on PMS concentration............... 4

Figure S4a. Molar spectra of phen and $\mathrm{Hphen}^{+}$obtained by combined pH-potentiometric and spectrophotometric method.

Figure S4b. Molar spectra of phenO and $\mathrm{HphenO}^{+}$obtained by combined $\mathrm{pH}$-potentiometric and spectrophotometric method.. .5

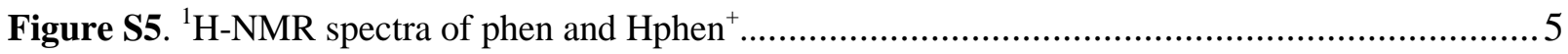

Figure S6. Dependence of the chemical shifts of the protons of phenO on the $\mathrm{pH}$...........................6

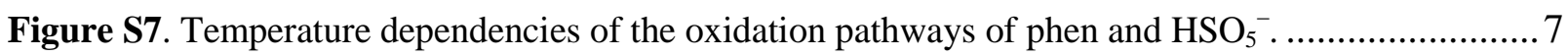

Figure S8. Kinetic traces obtained in the reaction between phen and PMS in the presence of excess phen..

Figure S9. Electrospray ionization mass spectrometric identification of 1,10-phenanthroline- $N, N^{\prime}$ dioxide in the reaction of phen and PMS. 8 
Figure S10. Spectral changes in the reaction between phen and PMS in nearly neutral medium.. 8

Figure S11. Kinetic traces obtained in the reaction between phen and PMS in nearly neutral medium.. 9

Figure S12. Normalization of the 6 kinetic curves shown in Figure 7..

Figure S13. Calculated spectra of the intermediate (I) and the product $(\mathrm{P})$ of the reaction between phen and PMS.

Figure S14. Calculated concentration profiles of the species in the reaction between phen and PMS in neutral medium.

\section{Tables}

Table S1. The first 10 singular values (SV) of the time-resolved UV-Vis absorbance matrices of the phen - PMS reaction in acidic medium.

Table S2. The rate constant of the reaction between phen and PMS at various reactant concentrations under acidic conditions.

Table S3. Effect of ionic strength on the rate of the reaction between phen and PMS.

Table S4. Temperature dependencies of the $\mathrm{p} K_{\mathrm{a}}$ of $\mathrm{Hphen}^{+}$and the rate constants of the two oxidation paths of the reaction between phen and PMS.

Table S5. The first 10 singular values (SV) of the time-resolved UV-Vis absorbance matrices of the phen - PMS reaction in neutral medium 


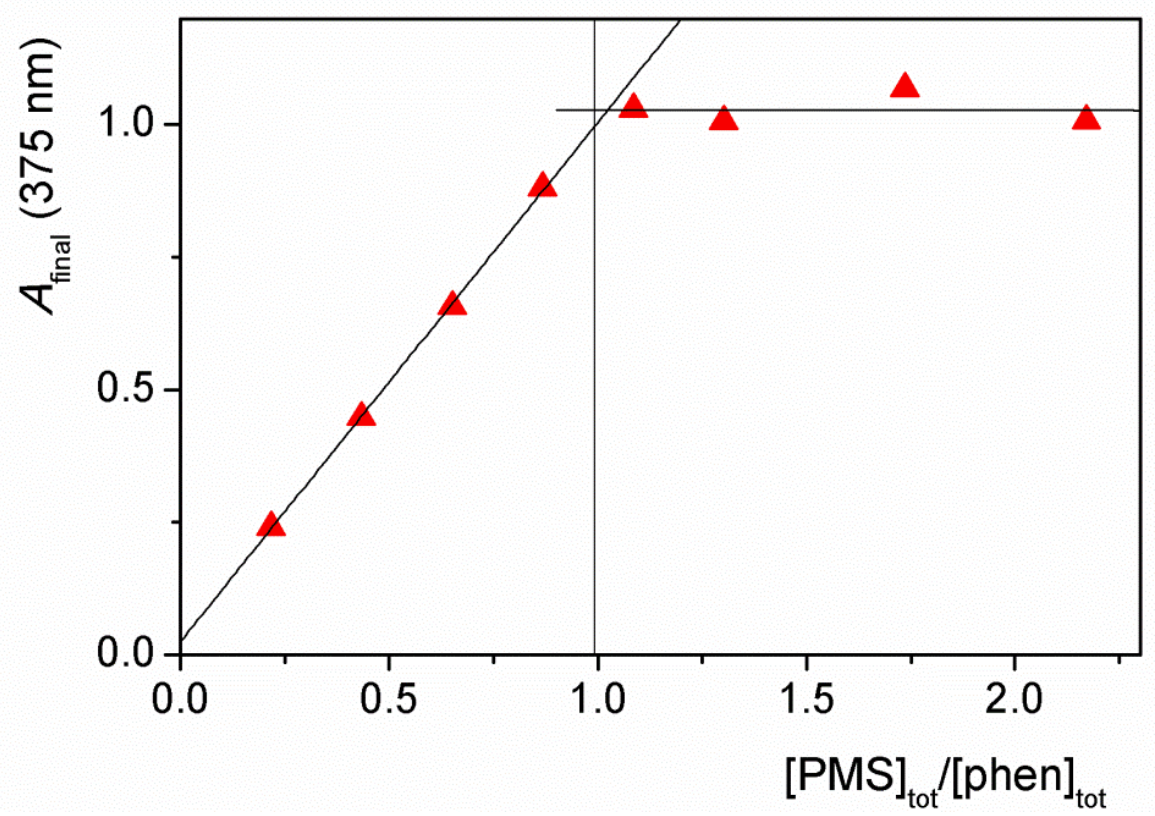

Figure S1. Spectrophotometric determination of the stoichiometry of the reaction of phen and PMS.

Different amounts of PMS were added to $462 \mu \mathrm{M}$ phen and the final absorbance readings of the kinetic curves were plotted against the ratio of the reactants. $\left[\mathrm{H}_{2} \mathrm{SO}_{4}\right]=1.00 \mathrm{M} ; t=40.0{ }^{\circ} \mathrm{C} ; \lambda=375 \mathrm{~nm}$; path length $1.000 \mathrm{~cm}$.

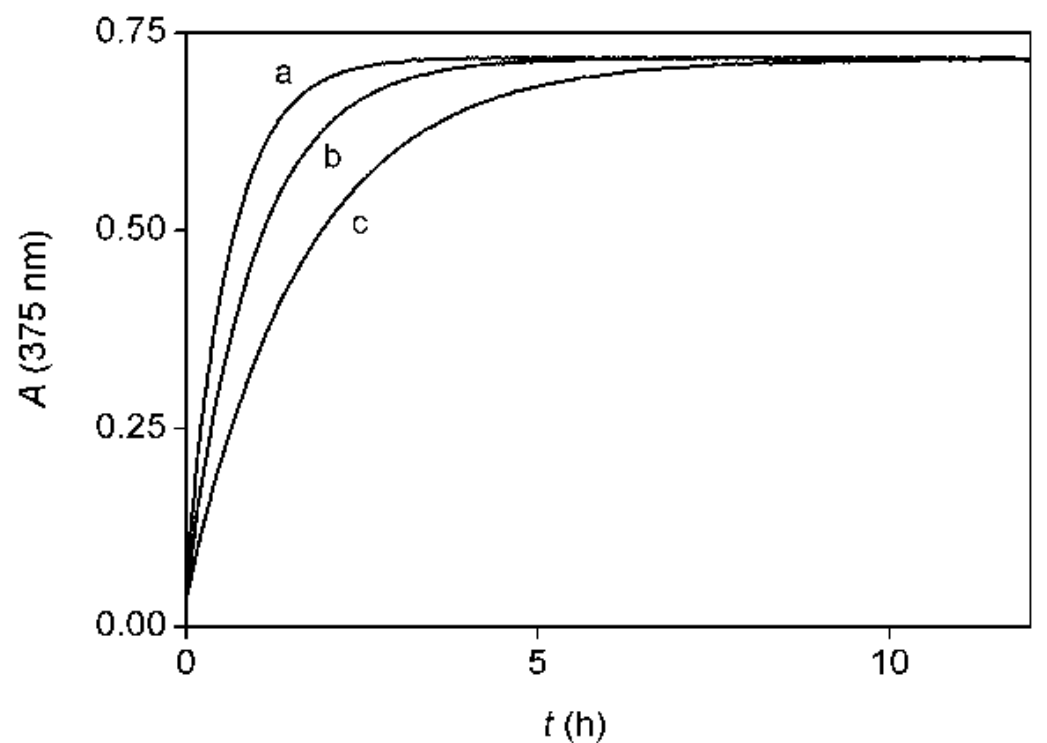

Figure S2. Kinetic traces of the reaction of phen and PMS under strongly acidic conditions. $[\text { phen }]_{0}=0.321 \mathrm{mM} ;\left[\mathrm{H}_{2} \mathrm{SO}_{4}\right]=1.00 \mathrm{M} ;[\mathrm{PMS}]_{0}=70.9 \mathrm{mM}(\mathrm{a}) ; 45.1 \mathrm{mM}(\mathrm{b}) ; 25.8 \mathrm{mM}(\mathrm{c}) ; t=25.0{ }^{\circ} \mathrm{C}$; $\lambda=375 \mathrm{~nm}$; path length $1.000 \mathrm{~cm}$. 


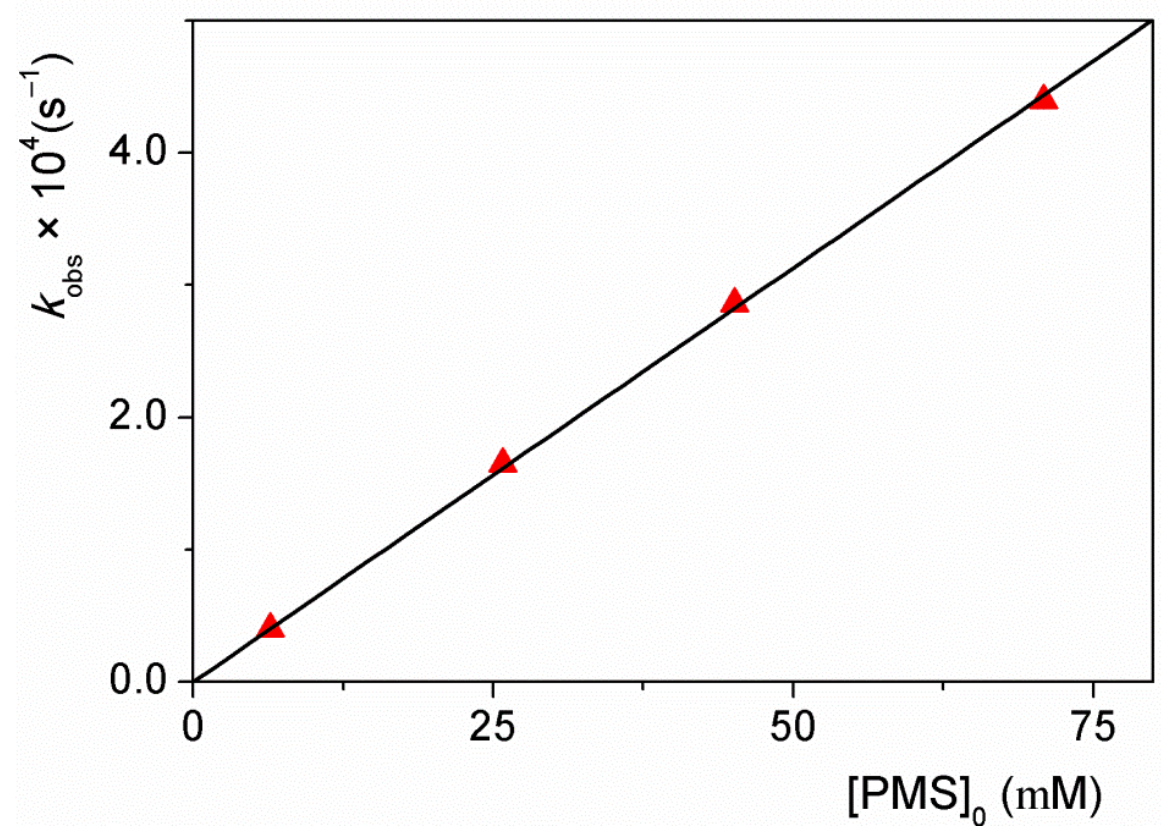

Figure S3. Dependence of the pseudo-first order rate constants $\left(k_{\mathrm{obs}}\right)$ on PMS concentration. $[\text { phen }]_{0}=0.321 \mathrm{mM} ;\left[\mathrm{H}_{2} \mathrm{SO}_{4}\right]=1.00 \mathrm{M} ; t=25.0^{\circ} \mathrm{C}$.

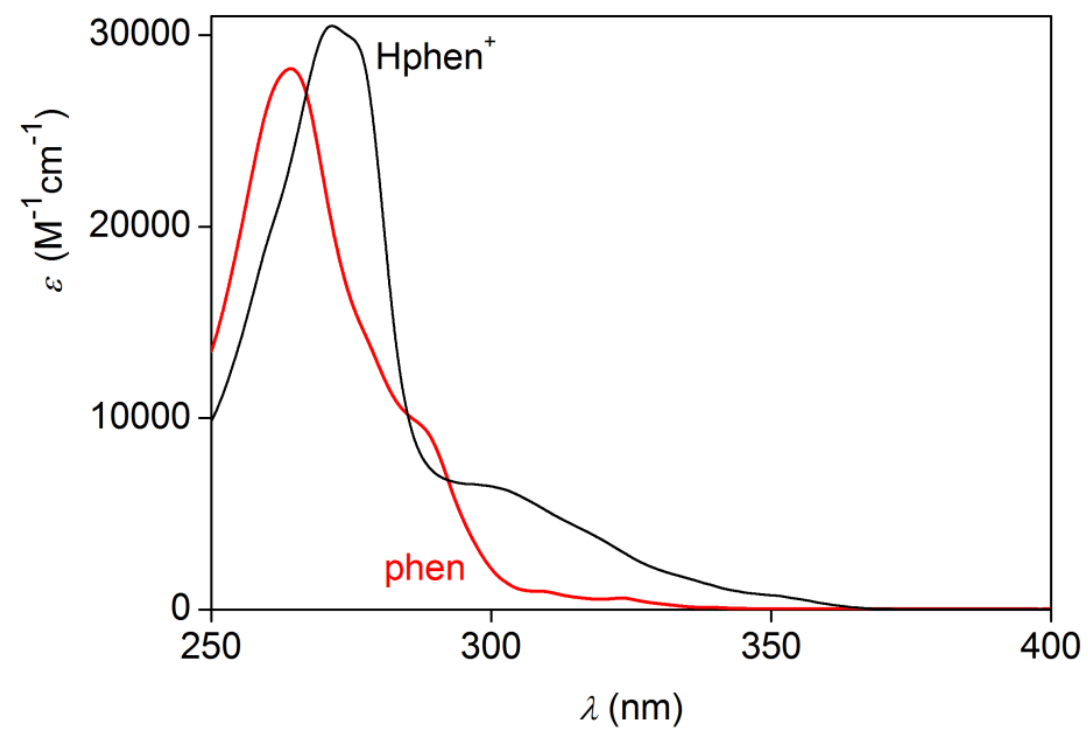

Figure S4a. Molar spectra of phen and $\mathrm{Hphen}^{+}$obtained by combined pH-potentiometric and spectrophotometric method. 


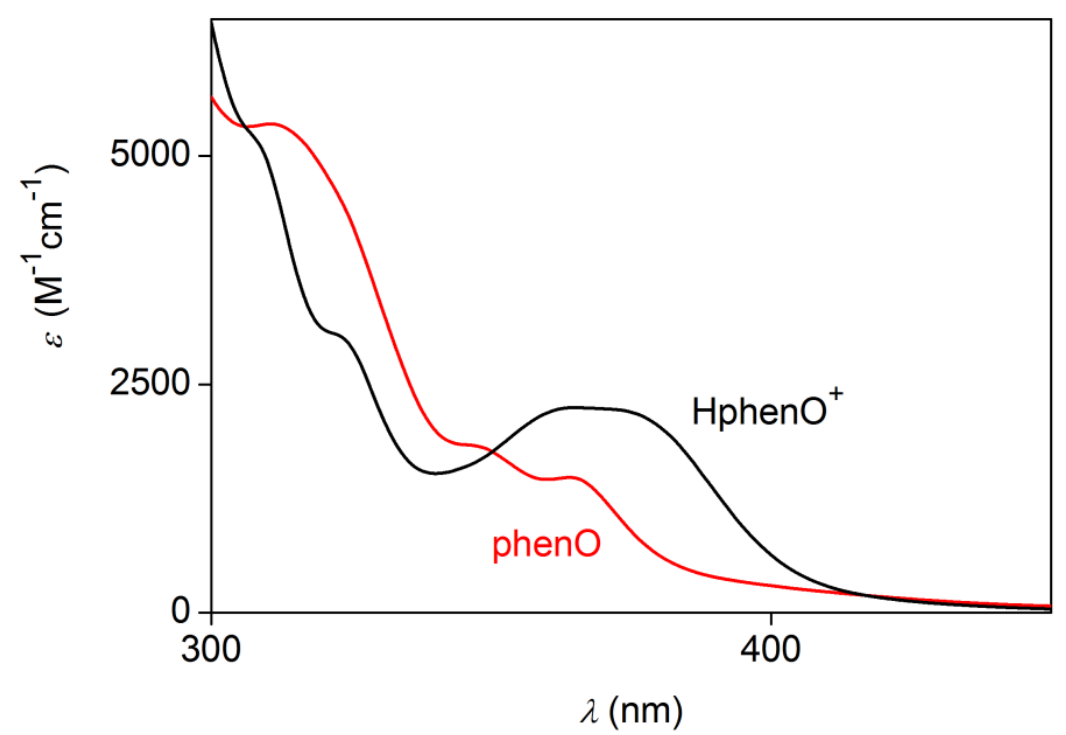

Figure S4b. Molar spectra of phenO and $\mathrm{HphenO}^{+}$obtained by combined $\mathrm{pH}$-potentiometric and spectrophotometric method.

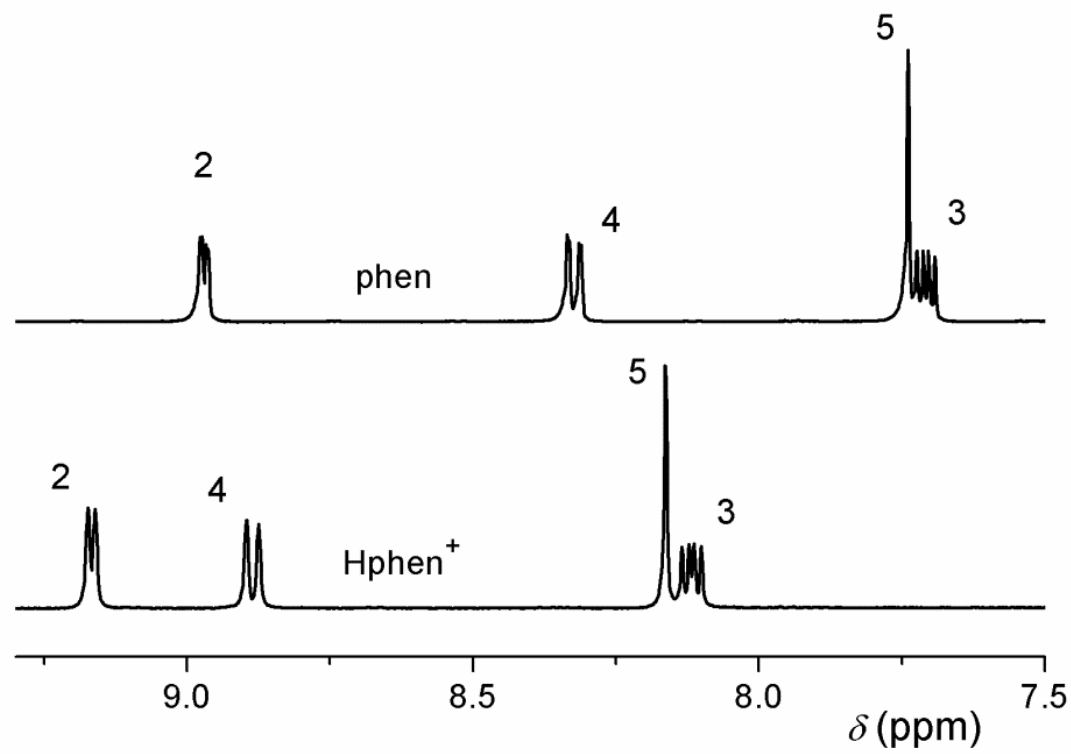

Figure S5. ${ }^{1} \mathrm{H}-\mathrm{NMR}$ spectra of phen and $\mathrm{Hphen}^{+}$at $25.0{ }^{\circ} \mathrm{C}$ in $\mathrm{H}_{2} \mathrm{O}\left([\mathrm{phen}]_{\mathrm{tot}}=5.0 \mathrm{mM}\right)$. The numbering of the aromatic system is in accordance with Scheme 1. 


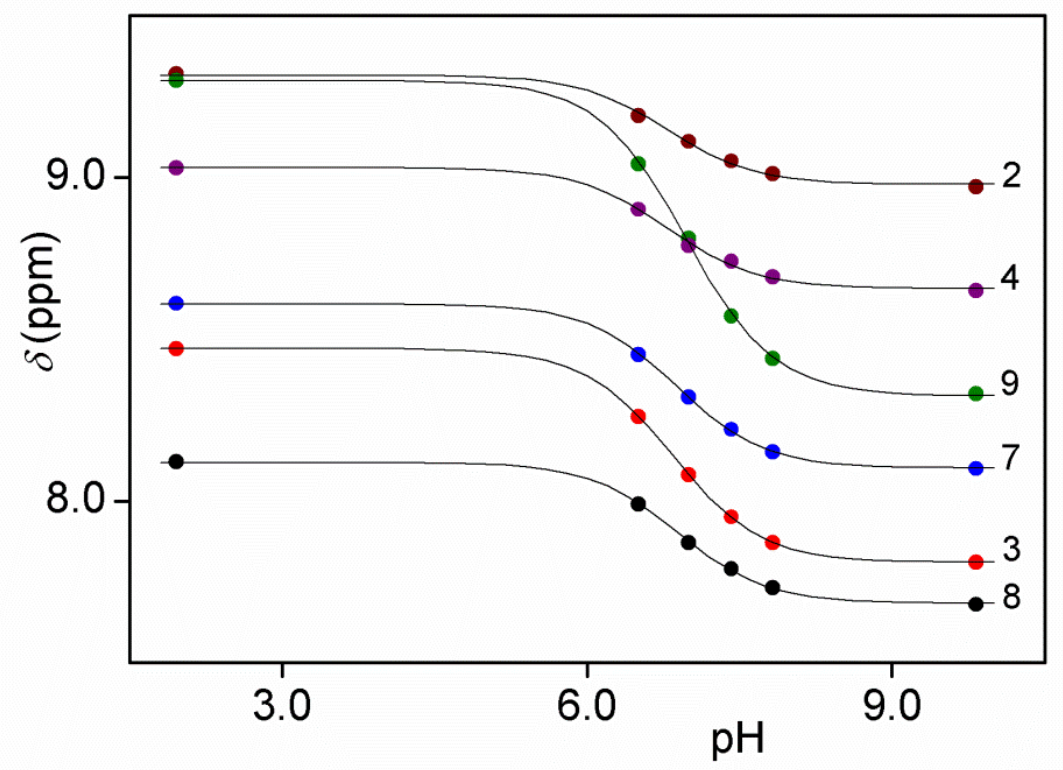

Figure S6. Dependence of the chemical shifts of the protons of phenO on the $\mathrm{pH}$. $[\mathrm{phenO}]_{\mathrm{tot}}=5.5 \mathrm{mM}$; $I=0.20 \mathrm{M} ; t=25.0{ }^{\circ} \mathrm{C}$; solvent: $\mathrm{H}_{2} \mathrm{O}$. The numbering of the aromatic system is in accordance with Scheme 1. Circles: experimental data. Lines: results of simultaneous nonlinear fit to the following equation:

$$
\delta_{\mathrm{pH}}=\frac{\delta_{\mathrm{HA}} \times[\mathrm{H}]^{+}+\delta_{\mathrm{A}} \times K_{\mathrm{a}}^{\text {phenO }}}{\left[\mathrm{H}^{+}\right]+K_{\mathrm{a}}^{\text {phenO }}}
$$

In this equation, $\delta_{\mathrm{pH}}$ is the chemical shift measured at a given $[\mathrm{H}]^{+}, \delta_{\mathrm{HA}}$ and $\delta_{\mathrm{A}}$ are the chemical shifts for the protonated and deprotonated forms of phenO and $K_{\mathrm{a}}{ }^{\text {phenO }}$ is the acid dissociation constant of $\mathrm{HphenO}^{+}$. 


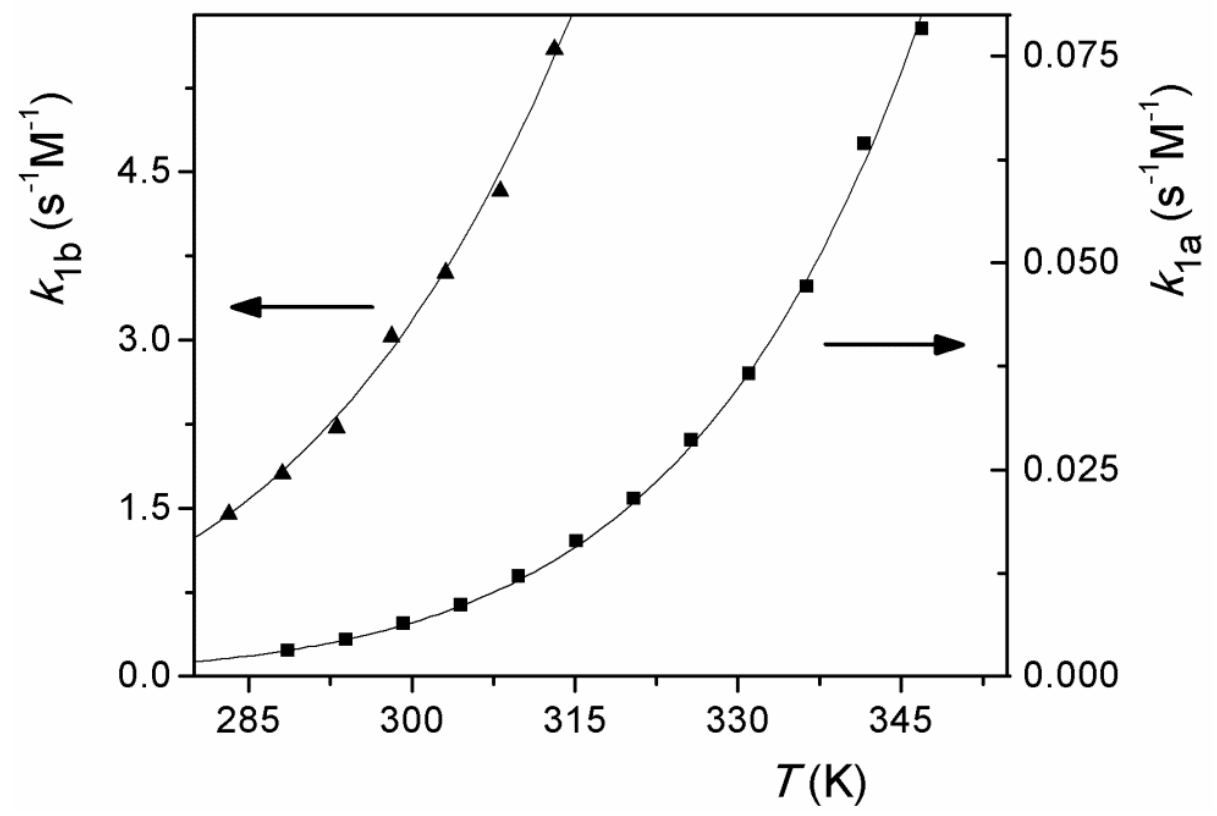

Figure S7. Temperature dependencies of the oxidation pathways of 1,10-phenanthroline and $\mathrm{HSO}_{5}{ }^{-}$. Triangles (left axis): rate constants of the oxidation of phen by $\mathrm{HSO}_{5}{ }^{-}$(eq. 1b); [phen $]_{0}=0.242 \mathrm{mM}$; $\left[\mathrm{HSO}_{5}{ }^{-}\right]_{0}=2.50 \mathrm{mM} ;$ [acetate $_{\text {tot }}=50.0 \mathrm{mM} ; I=1.00 \mathrm{M}\left(\mathrm{NaNO}_{3}\right)$

Squares (right axis): rate constants of the oxidation of $\mathrm{Hphen}^{+}$by $\mathrm{HSO}_{5}{ }^{-}$(eq. 1a) $[\mathrm{phen}]_{0}=0.242 \mathrm{mM}$; $\left[\mathrm{H}_{2} \mathrm{SO}_{4}\right]=1.00 \mathrm{M} ;\left[\mathrm{HSO}_{5}^{-}\right]_{0}=12.1 \mathrm{mM}$

Lines: results of the nonlinear fit to the Eyring equation (eq. 7).

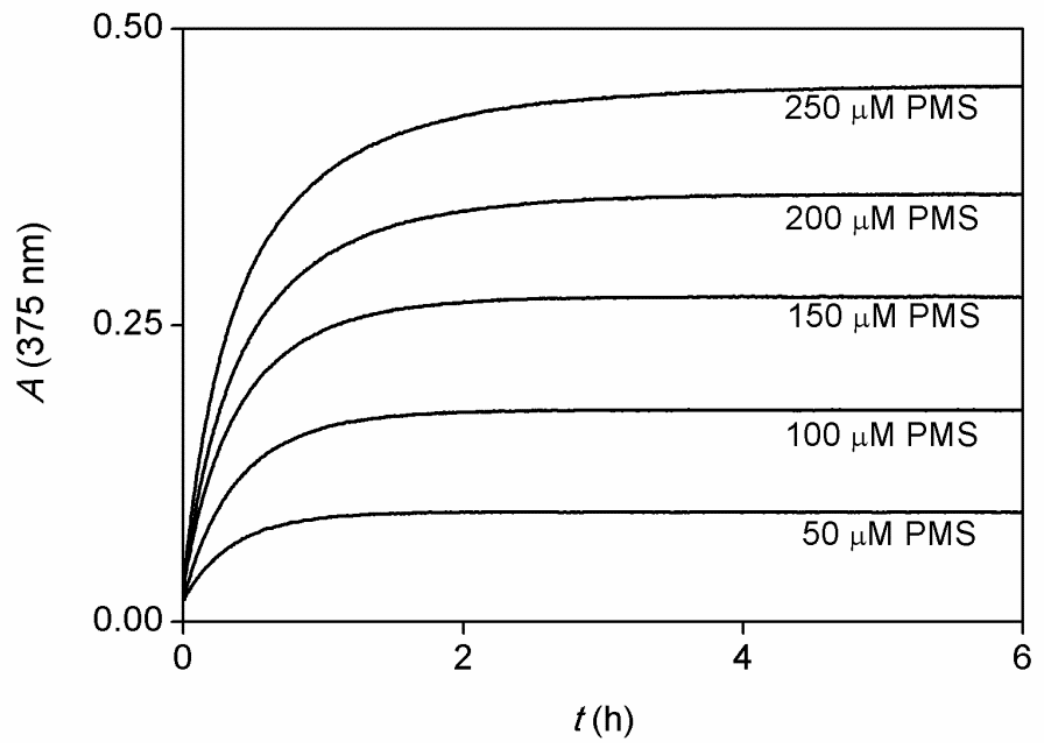

Figure S8. Kinetic traces obtained in the reaction between phen and PMS in the presence of excess phen. $[\text { phen }]_{0}=299 \mu \mathrm{M} ;[\text { phosphate }]_{\mathrm{tot}}=8.00 \times 10^{-2} \mathrm{M} ; \mathrm{pH}=6.7 ; I=1.00 \mathrm{M}\left(\mathrm{NaNO}_{3}\right) ; t=25.0{ }^{\circ} \mathrm{C} ; \lambda=375 \mathrm{~nm}$; path length $1.000 \mathrm{~cm}$. 

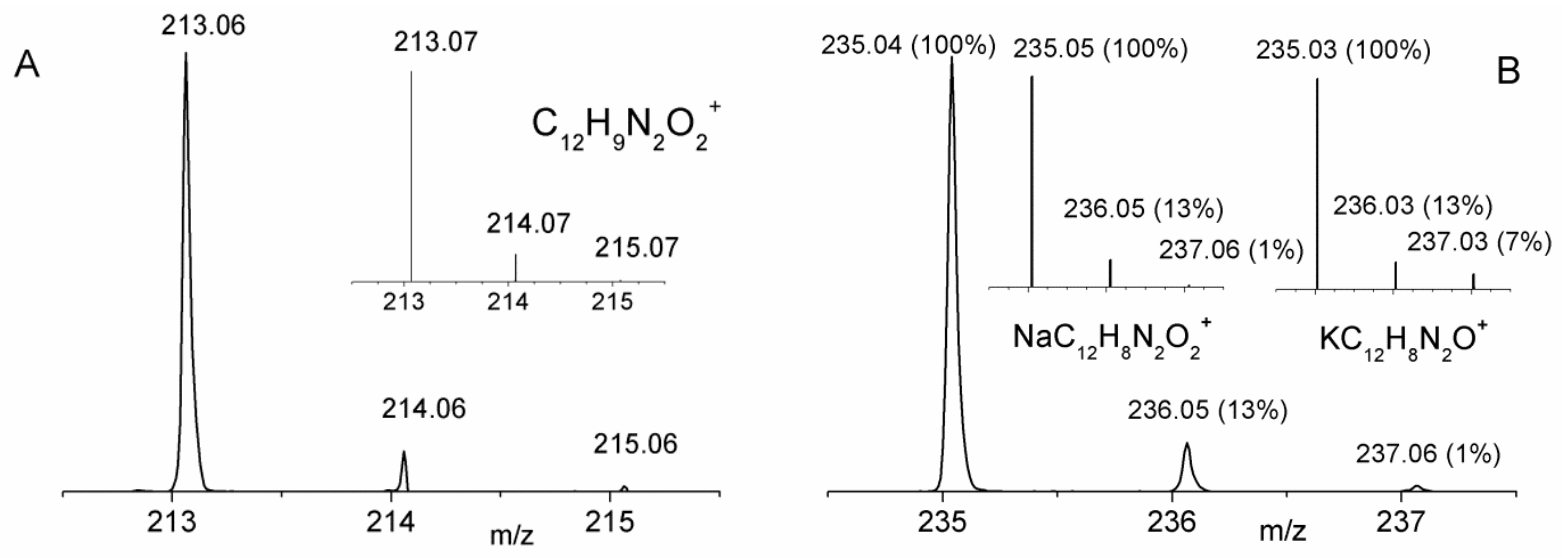

Figure S9. Electrospray ionization mass spectrometric identification of 1,10-phenanthroline- $N, N$ '-dioxide in the reaction of phen and PMS. [phen] $=0.75 \mathrm{mM} ;[\mathrm{PMS}]=2.0 \mathrm{mM} ;[\text { phosphate }]_{\mathrm{tot}}=9.0 \mathrm{mM} ; \mathrm{pH}=6.6$. A: identification of the protonated dioxide $\left(\mathrm{HphenO}_{2}{ }^{+}\right)$. Inset: calculated spectrum for the formula $\mathrm{C}_{12} \mathrm{H}_{9} \mathrm{~N}_{2} \mathrm{O}_{2}{ }^{+}$. B: identification of the dioxide ionized with sodium ion $\left(\mathrm{Na} \cdot \mathrm{phenO}_{2}{ }^{+}\right)$. Left inset: calculated spectrum for the formula $\mathrm{NaC}_{12} \mathrm{H}_{8} \mathrm{~N}_{2} \mathrm{O}_{2}{ }^{+}$. Right inset: calculated spectrum for the formula $\mathrm{KC}_{12} \mathrm{H}_{8} \mathrm{~N}_{2} \mathrm{O}^{+}$ (monoxide ionized with potassium ion). The isotopic distribution of the peaks clearly show that although the potassium ion adduct bears peaks of similar $\mathrm{m} / \mathrm{z}$ ratio, the $\left\{\mathrm{Na} \cdot \mathrm{phenO}_{2}\right\}$ cation was found in the reaction mixture.

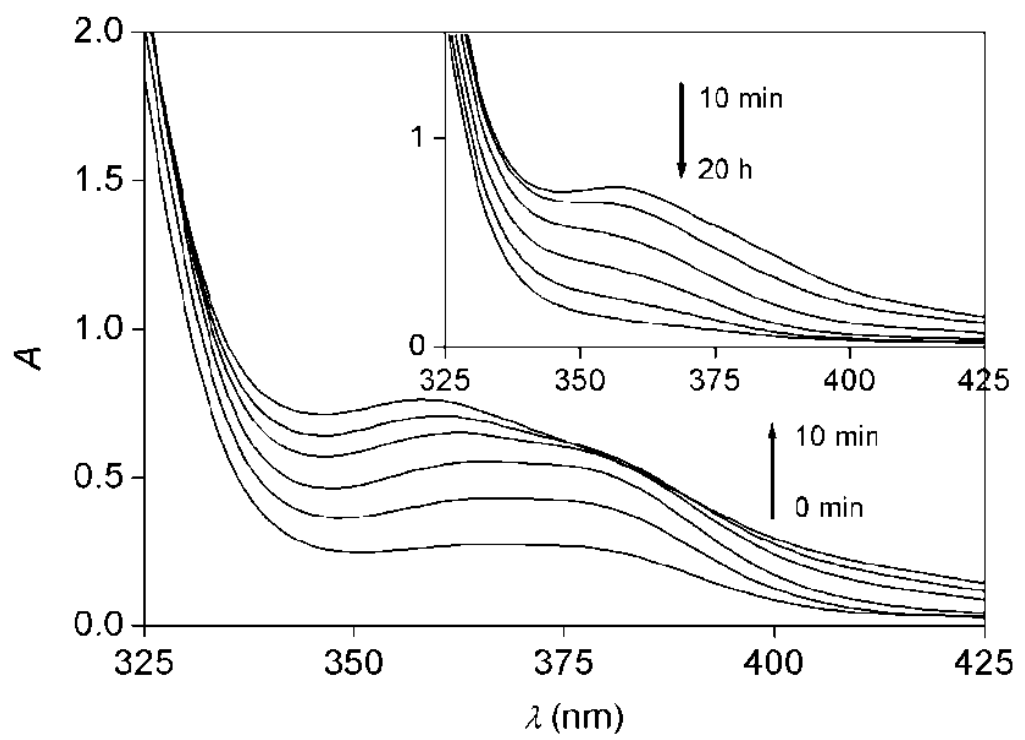

Figure S10. Spectral changes in the reaction between phen and PMS in nearly neutral medium. $[\mathrm{PMS}]_{0}=15.5 \mathrm{mM} ;[\mathrm{phen}]_{0}=0.259 \mathrm{mM} ;[\text { phosphate }]_{\mathrm{tot}}=8.00 \times 10^{-2} \mathrm{M} ; \mathrm{pH}=6.7 ; I=1.00 \mathrm{M}\left(\mathrm{NaNO}_{3}\right)$; $t=25.0^{\circ} \mathrm{C}$; path length $1.000 \mathrm{~cm}$. 

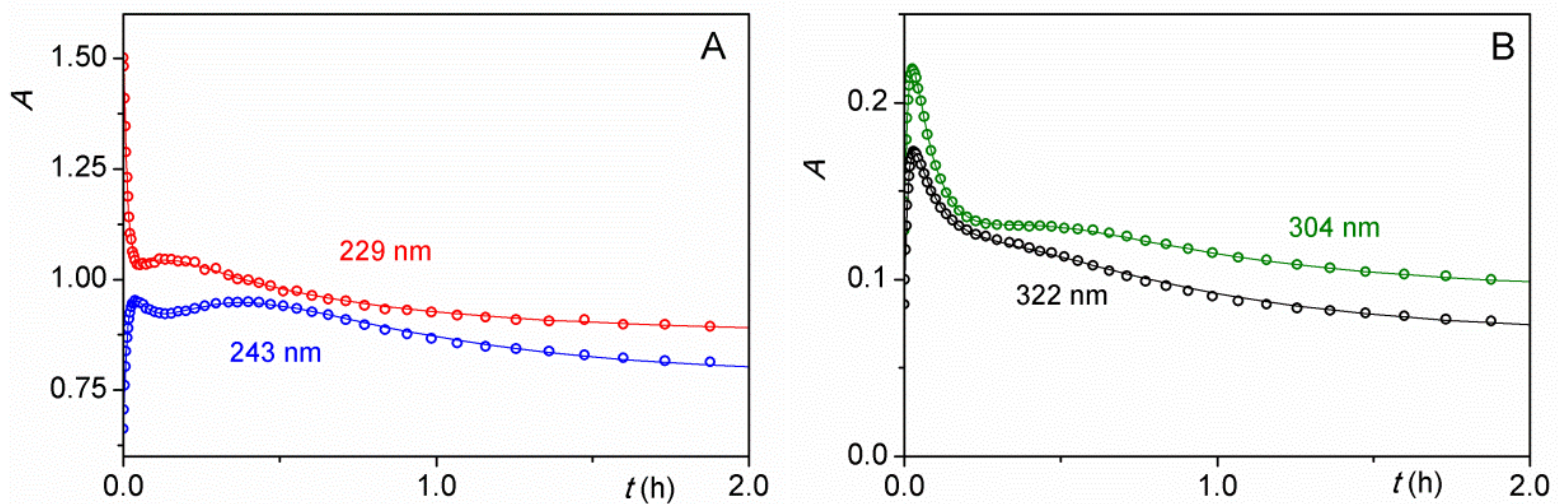

Figure S11. Kinetic traces obtained in the reaction between phen and PMS in nearly neutral medium. $[\mathrm{PMS}]_{0}=7.62 \mathrm{mM} ;[\mathrm{phen}]_{0}=0.100 \mathrm{mM} ;[\text { phosphate }]_{\text {tot }}=0.100 \mathrm{M} ; \mathrm{pH}=6.7 ; t=25.0{ }^{\circ} \mathrm{C}$; path length $0.500 \mathrm{~cm} . \mathbf{A}: \lambda=229$ and $243 \mathrm{~nm} . \mathbf{B}: \lambda=304$ and $322 \mathrm{~nm}$.

Open circles: experimental data. Only $20 \%$ of the recorded points are shown for clarity. Lines: results of nonlinear fit to the model described by eqs. 1 and 8-11.

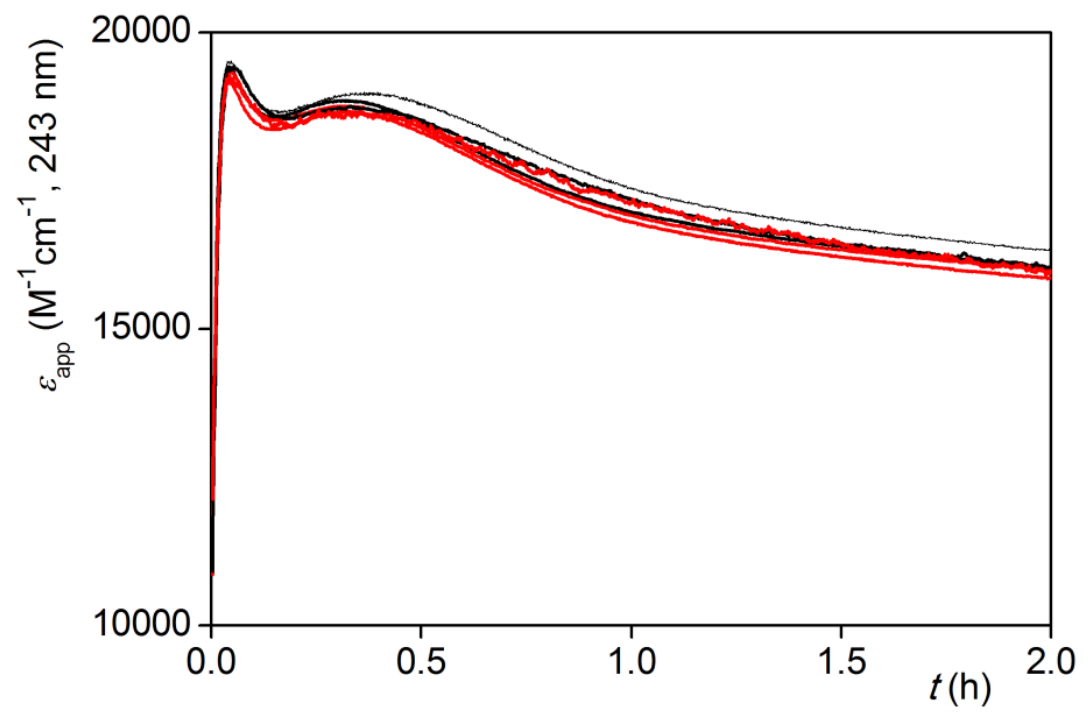

Figure S12. Normalization of the 6 kinetic curves shown in Figure 7. $\varepsilon_{\text {app }}$ is obtained by subtracting the nearly constant contribution of PMS from the detected absorbance and the division of the residual curves by the total concentration of phen.

$[\mathrm{PMS}]_{0}=9.77 \mathrm{mM} ;[\text { phen }]_{0}=7.62 \mu \mathrm{M} ; 12.7 \mu \mathrm{M} ; 25.4 \mu \mathrm{M} ; 38.1 \mu \mathrm{M} ; 50.8 \mu \mathrm{M}$ and $76.2 \mu \mathrm{M}$; [phosphate $]_{\mathrm{tot}}=1.01 \times 10^{-1} \mathrm{M} ; \mathrm{pH}=6.7 ; t=25.0^{\circ} \mathrm{C}, \lambda=243 \mathrm{~nm}$; path length $1.000 \mathrm{~cm}$. 


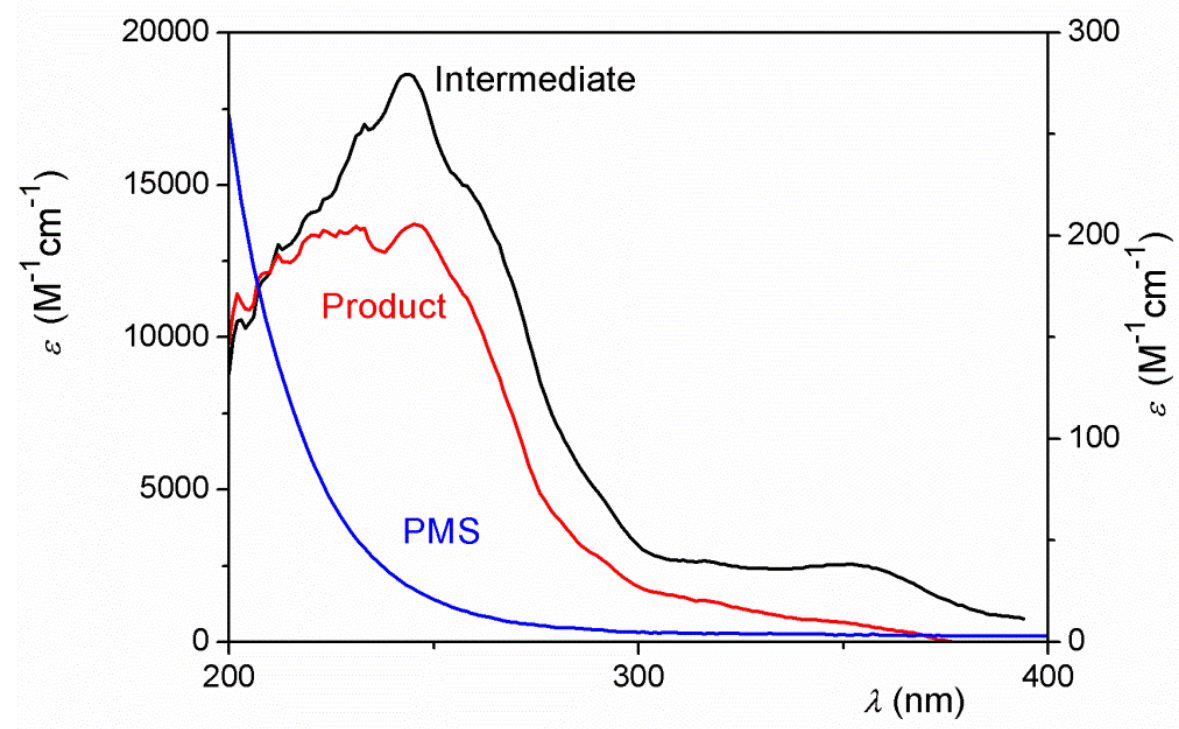

Figure S13. Left axis: Calculated spectra of the intermediate (I) and the product $(\mathrm{P})$ of the reaction between phen and PMS at pH 6.7 obtained by fitting a series of spectra to the model described by eqs. 1 and $8-11$.

Right axis: Spectrum of PMS at pH 6.7 obtained by combined $\mathrm{pH}$-potentiometric and spectrophotometric method.

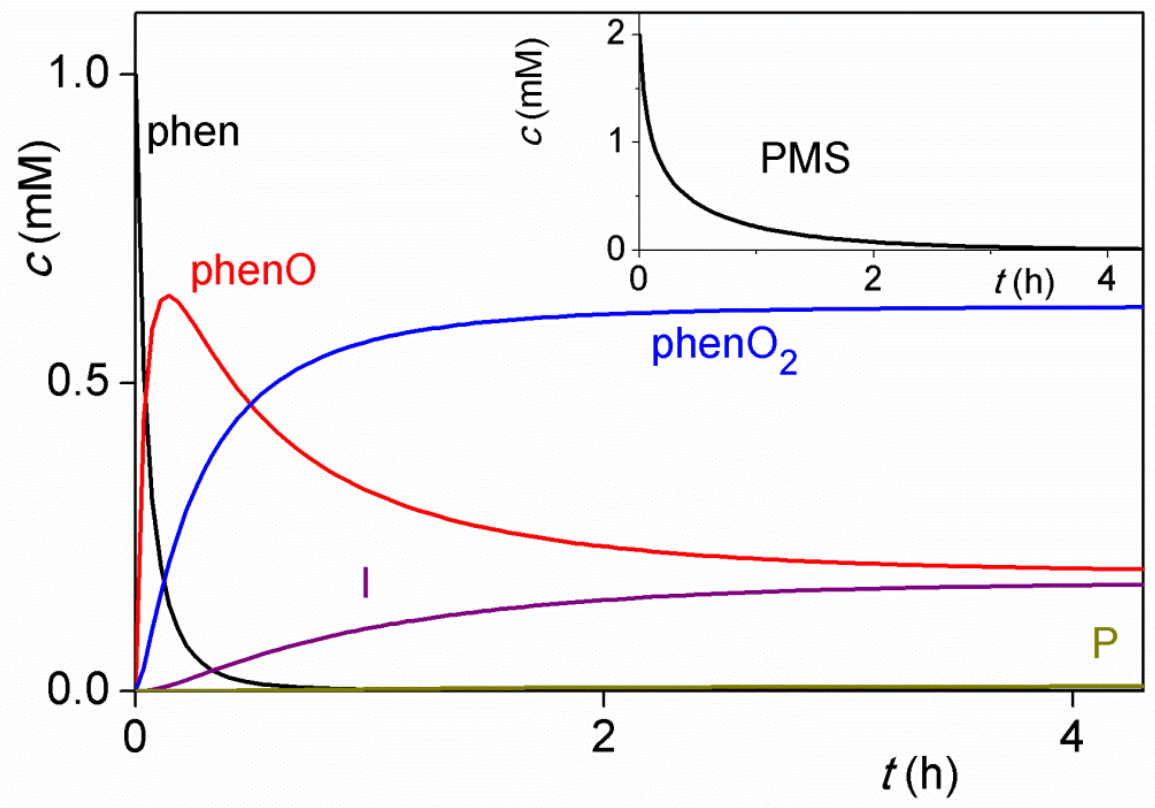

Figure S14. Calculated concentration profiles of the species in the reaction between phen and PMS in neutral medium $(\mathrm{pH}=6.7)$. $[\mathrm{PMS}]_{0}=2.00 \mathrm{mM} ;[\text { phen }]_{0}=1.00 \mathrm{mM} ; t=25.0{ }^{\circ} \mathrm{C}$. 
Table S1. The first 10 singular values (SV) of the time-resolved UV-Vis absorbance matrices of the phen - PMS reaction, recorded between $300-400 \mathrm{~nm}$ and under the given conditions. According to reference 39 , only the values in bold belong to real signal, the other nonzero elements represent experimental error.

\begin{tabular}{cc}
\hline $\begin{array}{c}27.4 \mathrm{mM} \text { PMS, } 0.234 \mathrm{mM} \text { phen } \\
t=25.0{ }^{\circ} \mathrm{C} ; \mathrm{pH} \sim 0\left(1.00 \mathrm{M} \mathrm{H}_{2} \mathrm{SO}_{4}\right)\end{array}$ & $\begin{array}{c}5.71 \mathrm{mM} \mathrm{PMS}, 0.357 \mathrm{mM} \text { phen } \\
\mathrm{SV}\end{array}$ \\
\hline $\mathbf{1 0 5 . 7}$ & $\mathbf{4 8 . 4 5}$ \\
$\mathbf{1 6 . 2 9}$ & $\mathbf{5 . 1 4 1}$ \\
0.187 & 0.0100 \\
0.136 & 0.0068 \\
0.025 & 0.0065 \\
0.013 & 0.0055 \\
0.012 & 0.0047 \\
0.012 & 0.0044 \\
0.011 & 0.0035 \\
0.010 & 0.0033 \\
\hline
\end{tabular}

Table S2. The rate constant of the reaction between phen and PMS at various reactant concentrations under acidic conditions. $\left[\mathrm{H}_{2} \mathrm{SO}_{4}\right]=1.00 \mathrm{M} ; t=25.0{ }^{\circ} \mathrm{C}$.

\begin{tabular}{cccc}
\hline$[\mathrm{PMS}]_{0}(\mathrm{mM})$ & {$[\mathrm{phen}]_{0}(\mathrm{mM})$} & $k_{\mathrm{obs}} \times 10^{4}\left(\mathrm{~s}^{-1}\right)$ & $k_{\mathrm{la}} \times 10^{3}\left(\mathrm{M}^{-1} \mathrm{~s}^{-1}\right)$ \\
\hline 11.9 & 0.056 & 0.781 & 6.58 \\
11.9 & 0.112 & 0.803 & 6.78 \\
11.9 & 0.224 & 0.739 & 6.22 \\
11.9 & 0.337 & 0.736 & 6.19 \\
11.9 & 0.505 & 0.731 & 6.17 \\
70.9 & 0.321 & 4.40 & 6.28 \\
45.1 & 0.321 & 2.86 & 6.36 \\
25.8 & 0.321 & 1.65 & 6.44 \\
6.44 & 0.321 & 0.403 & 6.39 \\
1.61 & 0.321 & - & 6.50 \\
0.805 & 0.321 & - & 6.36 \\
0.322 & 0.321 & - & 6.08 \\
\hline & & average: & $6.4 \pm 0.2$ \\
\hline
\end{tabular}


Table S3. Effect of ionic strength on the rate of the reaction between phen and PMS. $[\text { phen }]_{0}=0.212 \mathrm{mM} ;[\mathrm{PMS}]_{0}=2.15 \mathrm{mM} ;[\text { phosphate }]_{\mathrm{tot}}=2.00 \times 10^{-2} \mathrm{M} ; \mathrm{pH}=6.6 ; t=25.0{ }^{\circ} \mathrm{C}$.

\begin{tabular}{cc}
\hline$I(\mathrm{M})$ & $k_{1}\left(\mathrm{M}^{-1} \mathrm{~s}^{-1}\right)$ \\
\hline 0.11 & 2.84 \\
0.51 & 2.93 \\
0.81 & 2.93 \\
1.21 & 2.95 \\
1.61 & 3.02 \\
\hline average: & $2.93 \pm 0.06$
\end{tabular}

Table S4. Temperature dependencies of the $\mathrm{p} K_{\mathrm{a}}$ of $\mathrm{Hphen}^{+}$and the rate constants of the two oxidation paths of the reaction between phen and PMS. $k_{1 \mathrm{a}}$ was determined in $1.00 \mathrm{M} \mathrm{H}_{2} \mathrm{SO}_{4}$, in the case of the $\mathrm{p} K_{\mathrm{a}}$ and $k_{1 \mathrm{~b}}$ the ionic strength was kept constant by using $1.0 \mathrm{M} \mathrm{NaNO}_{3}$.

\begin{tabular}{cccc}
\hline$T(\mathrm{~K})$ & $k_{1 \mathrm{a}} \times 10^{3}\left(\mathrm{M}^{-1} \mathrm{~s}^{-1}\right)$ & $k_{1 \mathrm{~b}}\left(\mathrm{M}^{-1} \mathrm{~s}^{-1}\right)$ & $\mathrm{p} K_{\mathrm{a}}^{\text {phen }}$ \\
\hline 283 & 2.18 & 1.45 & $5.23(2)$ \\
288 & 3.08 & 1.82 & $5.25(2)$ \\
293 & 4.41 & 2.22 & $5.22(2)$ \\
298 & 6.35 & 3.03 & $5.14(2)$ \\
303 & 8.60 & 3.59 & $5.09(1)$ \\
308 & 12.1 & 4.33 & $5.03(2)$ \\
313 & 16.3 & 5.59 & $4.97(4)$ \\
318 & 21.4 & & \\
323 & 28.6 & & \\
328 & 36.7 & & \\
333 & 47.2 & & \\
338 & 64.4 & & \\
343 & 78.3 & & \\
\hline
\end{tabular}


Table S5. The first 10 singular values (SV) of the time-resolved UV-Vis absorbance matrices of the phen - PMS reaction, recorded between 200 - $400 \mathrm{~nm}$ under the conditions given below. Only values in bold belong to real species, the other nonzero elements represent experimental error. ${ }^{39}$ The analysis was carried out for increasing overall time range $\left(t_{\mathrm{oa}}\right)$ of the same spectral series.

$[\mathrm{phen}]_{0}=0.100 \mathrm{mM} ;[\mathrm{PMS}]_{0}=7.62 \mathrm{mM} ;[\text { phosphate }]_{\mathrm{tot}}=0.100 \mathrm{M} ; \mathrm{pH}=6.7 ; t=25.0{ }^{\circ} \mathrm{C}$

\begin{tabular}{cccc}
\hline$t_{\text {oa }}=107.3 \mathrm{~s}$ & $t_{\text {oa }}=501.6 \mathrm{~s}$ & $t_{\text {oa }}=1495.2 \mathrm{~s}$ & $t_{\text {oa }}=10699.5 \mathrm{~s}$ \\
$\mathrm{SV}$ & $\mathrm{SV}$ & $\mathrm{SV}$ & $\mathrm{SV}$ \\
\hline $\mathbf{6 6 . 6 7}$ & $\mathbf{1 0 0 . 5}$ & $\mathbf{1 1 9 . 5}$ & $\mathbf{1 4 1 . 9}$ \\
$\mathbf{3 . 8 0 1}$ & $\mathbf{5 . 3 5 9}$ & $\mathbf{8 . 6 1 0}$ & $\mathbf{1 7 . 1 9}$ \\
0.310 & $\mathbf{3 . 4 7 3}$ & $\mathbf{5 . 0 0 8}$ & $\mathbf{6 . 3 7 4}$ \\
0.134 & 0.322 & $\mathbf{2 . 0 5 6}$ & $\mathbf{4 . 1 5 9}$ \\
0.098 & 0.176 & 0.202 & $\mathbf{1 . 5 2 5}$ \\
0.092 & 0.152 & 0.190 & 0.241 \\
0.077 & 0.125 & 0.162 & 0.198 \\
0.070 & 0.107 & 0.134 & 0.176 \\
0.065 & 0.010 & 0.128 & 0.173 \\
0.061 & 0.094 & 0.125 & 0.155 \\
\hline
\end{tabular}

